Session $11-4$

\title{
Homework or Quiz?
}

\author{
Richard Bannerot \\ Department of Mechanical Engineering \\ University of Houston
}

\begin{abstract}
The test performances of students in three classes of the second course in engineering thermodynamics in a BSME program are compared on the basis on whether closed book quizzes (two classes) were used in place of the more traditional homework (one class). There were no measurable differences in testing performances among the three classes, but a positive correlation was demonstrated between better homework or quiz grades and testing grades. Copies of example of quizzes and an example project are provided. The results from student surveys indicate fairly strong support for the quizzes over homework and the use of a website over a more tradition format for the course. However, almost $25 \%$ of the students prefer a more tradition course format of weekly homework and writing on the board.
\end{abstract}

\section{Introduction}

The ultimate skill to be learned in an undergraduate engineering curriculum is "problem solving." Since essentially all engineering (and science) classes are limited to a narrow discipline, e.g., heat transfer, statics, dynamics, electrical circuits, etc., the problems worked are usually very limited in scope. Further, since the problems are assigned to follow the development of the concepts presented in class, many homework problems mimic the examples in the book. Many students depend on their ability to "match up" the problems they are trying to solve with the most similar example they can find. Students may also simply copy each other, or last year's solutions, or the current solution manual. These scenarios may have the negative result of creating false confidence for those who think that understanding comes from following someone else's solution.

Assigning homework in engineering classes has a long tradition. The premise is that one learns by doing, based on the assumption that everyone does his own homework and learns from the experience. The fact, however, is that many students receive help in completing their assignments. If the help is in the form of minor assistance or explanations, the result may still be good, but not as good as the result achieved by "working" out the problems oneself. It is evident in this information age that solution manuals for many standard engineering textbooks have achieved wide distribution and seem to be available to most if not all students. There are three ways that students could use the solutions manual:

- as a backup or resource of last resort in which a "hint" may be obtained after an unsuccessful but substantial effort has been made to work the problem, 
- as a "crutch" in which the solution is frequently referenced at each step to check intermediate answers and to "see what to do next", and

- as "easy picking", an assignment to be copied and turned in as ones own work, thus a useless activity.

From a grading standpoint, it is not worth the extra effort to distinguish among these three types of submissions. Therefore, we have a situation in which some students can achieve high "grades" on the homework, but learn little and fail the exams, while others achieve lower homework grades (without access to the solutions) and fair better on the exams (because they learned by figuring it out).

Thermodynamics II is the second of two required courses in classical engineering thermodynamics for our BSME program. The coverage for the three-hour credit course has been the same since the mid 1970s when our required thermodynamics sequence was reduced from three to two courses: vapor power cycles, gas power cycles, vapor compression and gas refrigeration, psychrometrics, and combustion. Currently, the course is taught each fall to about 60 to 70 students. There have been several instructors for the course, and author of this paper has taught it at least ten times, including the last three fall semesters (2005-7). Only one section of the course was taught in fall 2005, and two sections were taught in fall 2006 and in fall 2007. The course is taught face-to-face, but all materials including lecture notes are posted on a website (Blackboard).

\section{Methodology}

During the fall 2005 it became clear that most students had access to the solution manual since most homework submissions were essentially copies of the solutions in the manual. To counteract this trend, for the last two years, ten in-class, 15- to 20-minute closed book quizzes have been substituted, grade-wise, for the traditional homework assignments. (These quizzes were given weekly except when exams were scheduled.) Homework was still assigned as before, but none was submitted and solutions were posted. Students were instructed about the benefits of making a serious attempt to work, on their own, what were essentially additional examples. The quizzes were very narrow in scope, and the subject was announced about a week in advance. The announced material coverage for a quiz was commonly only two or three examples or a few selected pages from the textbook ${ }^{1}$. (The topics are listed in Appendix I at the end of this paper; sample quizzes are given in Appendix II.)

With this change in format (without change in content) two questions arose:

- Do students "learn" better when forced to perform on closed book quizzes throughout the semester than when they were on their own to work (or copy) the homework?

- Are the homework or quiz grades better predictors of exam performance?

Data for the past three years from Thermodynamics II is presented and analyzed in the paper. The data represents homework and test grades from 65 students for whom homework was required (one section in fall 2005) and from 132 students for whom quizzes were required (four sections in fall 2006 and fall 2007). The use of homework and quiz grades to predict exam 
grades is analyzed, and overall class performance (homework classes vs. quiz classes) is examined.

The grading schemes were slightly different each of the semesters (all tests and final exams were open book and open notes):

- For fall 2005 grading was based on the best three of four test grades at $20 \%$ each, the final exam at $30 \%$, and homework at $10 \%$.

- For fall 2006 grading was based on three exams at 17\% each, the final exam at 30\%, ten quizzes at $9 \%$, and a project at $10 \%$. The projects were assigned to students randomly by the instructor, and most were developed from the "end of the chapter problems" in the textbook ("Design and Open Ended Problems: Exploring Engineering Practice").

- For fall 2007 grading was based on three tests totaling 50\% (one at $10 \%$ over thermodynamics I material, and two at $20 \%$ each), the final exam for $35 \%$, ten quizzes for $15 \%$, and an extra credit project for up to $10 \%$. (The projects were selected by the students from a list of topics provided by the instructor. See Appendix III.)

All grades (homework, quiz, tests, and final exams) are reported on a four-point scale, the wellknown grade point average (i.e., 4.0 =A, 3.0=B, 2.0=C, $1.0=\mathrm{D}$ and $0=\mathrm{F}$ ). It is possible for grades on individual items to exceed 4.0, and occasionally grades as high as 4.5 were earned. All grading was done by the instructor. Homework and quiz grades were assigned on a linear scale without a "curve" where $50 \%$ correct corresponded to $2.0 / 4.0$ or a C. Tests and the final exams were graded on a similar basis according to a grading rubric developed for each test and exam in which the solution for each problem was broken up into as many as 20 parts for the purpose of assigning partial credit. Tests and exams were constructed such that a grade of 90/100 was the expectation for an A (4.0/4.0); 75/100, a B (3.0/4.0),60/100, a C (2.0/4.0), etc. After the test or exam was graded, the scale may have been adjusted downward slightly (i.e., the grades adjusted upward) e.g., 55/100 may become a $\mathrm{C}$ instead of 60/100 with an associated adjustment for other grades; there was never any upward adjustment of the scale, i.e., grades were never adjusted downward. Exams from previous classes were posted with solutions. There were three versions of each exam in 2005 and four versions of each exam (two for each section) in 2006 and 2007.

\section{Results}

Based in the grading scheme discussed above, the average grades (followed by the standard deviation (SD) for each grouping) for the various elements of the course the last three years are tabulated in Table 1. For 2006 and 2007 the grades for the two sections are combined. The results in row 3 indicate that the answer to the first question, "Do students learn more from preparing for the quizzes than they do by doing homework?" is, "no", as there are only negligible differences in the average grades for the classes $(2.65,2.71,2.63)$ over the three years. 
Table 1. Grades Based on a 4.0 Point Scale for Thermodynamics II for the Last Three Years

\begin{tabular}{|c|c|c|c|c|}
\hline 1 & & 2005 & 2006 & 2007 \\
\hline 2 & No. in class & 65 & $72 *$ & $60 *$ \\
\hline 3 & Course gpa \pm SD & $2.64 \pm 0.71$ & $2.71 \pm 0.63$ & $2.63 \pm 0.91$ \\
\hline 4 & Text & \multicolumn{3}{|c|}{ Moran \& Shapiro for all five sections } \\
\hline 5 & Coverage & \multicolumn{3}{|c|}{ Review: Chapters: 1-7,11; New: Chapters: $8,9,10,12,13$} \\
\hline 6 & & & & \\
\hline 7 & $\mathrm{HW}$ avg $\pm \mathrm{SD}$ & $3.38 \pm 0.54$ & - & - \\
\hline 8 & Quiz avg \pm SD & & $3.08 \pm 0.61$ & $2.66 \pm 0.68$ \\
\hline 9 & & & & \\
\hline 10 & Test avg \pm SD & $2.42 \pm 0.81$ & $2.56 \pm 0.89$ & $2.05 \pm 0.83$ \\
\hline 11 & Final Exam avg \pm SD & $2.16 \pm 0.92$ & $2.26 \pm 0.88$ & $2.52 \pm 0.85$ \\
\hline 12 & & & & \\
\hline 13 & HW minus Test & $0.95 \pm 0.85$ & - & - \\
\hline 14 & Quiz minus Test & - & $0.53 \pm 0.93$ & $0.61 \pm 0.76$ \\
\hline 15 & & & & \\
\hline 16 & HW minus Final Exam & $1.21 \pm 1.03$ & - & - \\
\hline 17 & Quiz minus Final Exam & - & $0.82 \pm 0.88$ & $0.14 \pm 0.94$ \\
\hline 18 & & & & \\
\hline 19 & HW minus all testing** & $1.04 \pm 0.84$ & - & - \\
\hline 20 & $\begin{array}{l}\text { Quiz minus all } \\
\text { testing*** }\end{array}$ & - & $0.63 \pm 0.81$ & $0.42 \pm 0.75$ \\
\hline
\end{tabular}

$*$ total enrollment in two sections in 2006 and 2007

**2005: best 3 of 4 tests at $20 \%$ each plus final at 30\% (homework: $10 \%$ )

***2006: 3 tests at 17\% each plus final exam at 30\% (Quizzes: 9\%; project 10\%)

2007: 3 tests at 10, 20 and 20\% plus final exam at 35\% (Quizzes: 15\%; extra credit project $10 \%$ )

The homework grades (2005) and the quiz grades (2006 and 2007) are given in rows 7 and 8. The average test and final exam grades are given in rows 10 and 11 . In rows 13 and 14 the differences between the homework or quiz averages and the test averages are given. In rows 16 and 17 the differences between the homework or quiz averages and the final exam averages are given. Finally, in rows 19 and 20 the differences between the homework or quiz averages and the averages for all (open book) testing are given.

Generally, the differences between the testing grades and the homework grades are greater for 2005 than the differences between the testing grades and the quiz grades for the combined 2006 and 2007 classes, but this difference is due primarily to the differences between the quiz and homework grades and not the differences between the testing grades for 2005 compared to 2006 and 2007.

Figure 1 is a plot of the differences between individual testing grades and the associated individual homework grades on the ordinate (for 2005) as a function of the individual testing grades. Figure 2 and 3 are plots of the differences between individual testing grades and the associated individual quiz grades (for 2006 and 2007) as a function of the individual testing

Proceedings of the 2008 ASEE Gulf-Southwest Annual Conference

The University of New Mexico - Albuquerque

Copyright (C) 2008, American Society for Engineering Education 
grades. If there were a direct correlation between the testing and homework (or quiz) grades and the corresponding testing grades, the trend line in the figures would be horizontal. If the grades were actually the same, the trend line would be at $y=0$. As seen in the figures there is no direct correlation, but there is a weak correlation indicating that for both homework and the quizzes, the better testing students tended to score better on the homework and on the quizzes (as expected). However, there is little indication that the quiz grades are a better predictor of testing performance than are homework grades. Hence, the answer to the second question is also, "no".

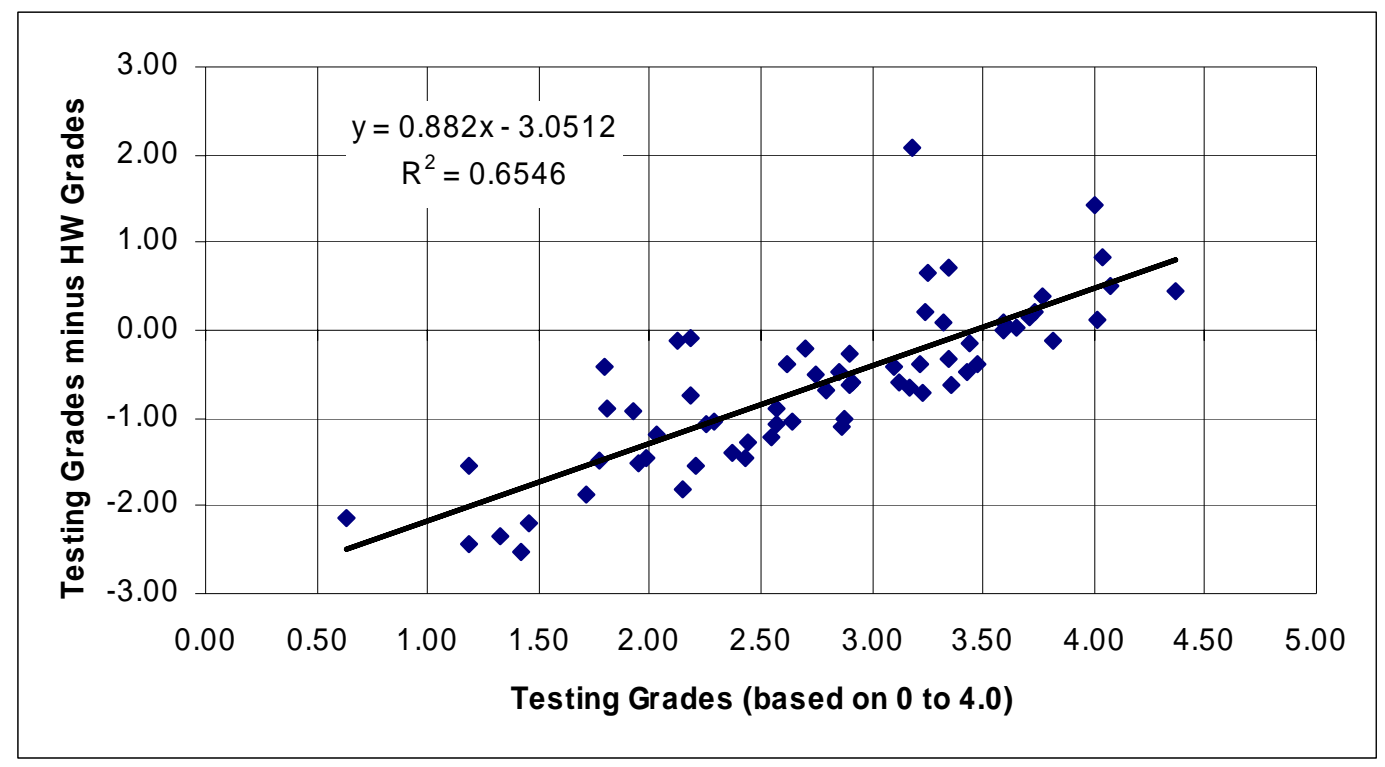

Figure 1. Testing Grades Minus Homework Grades vs. Testing Grades (Fall 2005)

\section{Student Survey}

End-of-the-semester surveys were administered in the 2006 and 2007 classes. Students were asked to respond on a 5-point Likert Scale (5 = "strongly agree; $4=$ "agree"; $3=$ "no preference"; 2 = "disagree"; and 1 = "strongly disagree") to a series of statements related to their opinion of their learning and the conduct of the class (related mostly to the issues of requiring homework or quizzes and of using a website, utilizing Blackboard software, in the teaching of the course). Some of the responses are summarized in Table 2. A total of 137 students registered for the course in 2006 and 2007; five dropped before the final and four did not pass. The survey was administered during class, and 121 submitted the surveys. Not all students provided responses to all statements. The statement is given in the middle of Table 2 (sometimes edited to fit the space available) with the average responses for 2006 (first column), for 2007 (second column), and for both years in the third column (avg.). The distributions of responses for both years combined are given in the last five columns beginning with "5-strongly agree".

The first nine statements indicate that the students feel more comfortable using property tables to solve vapor and gas power cycles and vapor compression refrigeration cycles problems than IC engines, psychrometric or combustion problems. As noted in previous classes, but not documented, some students have confusion over the difference between using the air tables and 


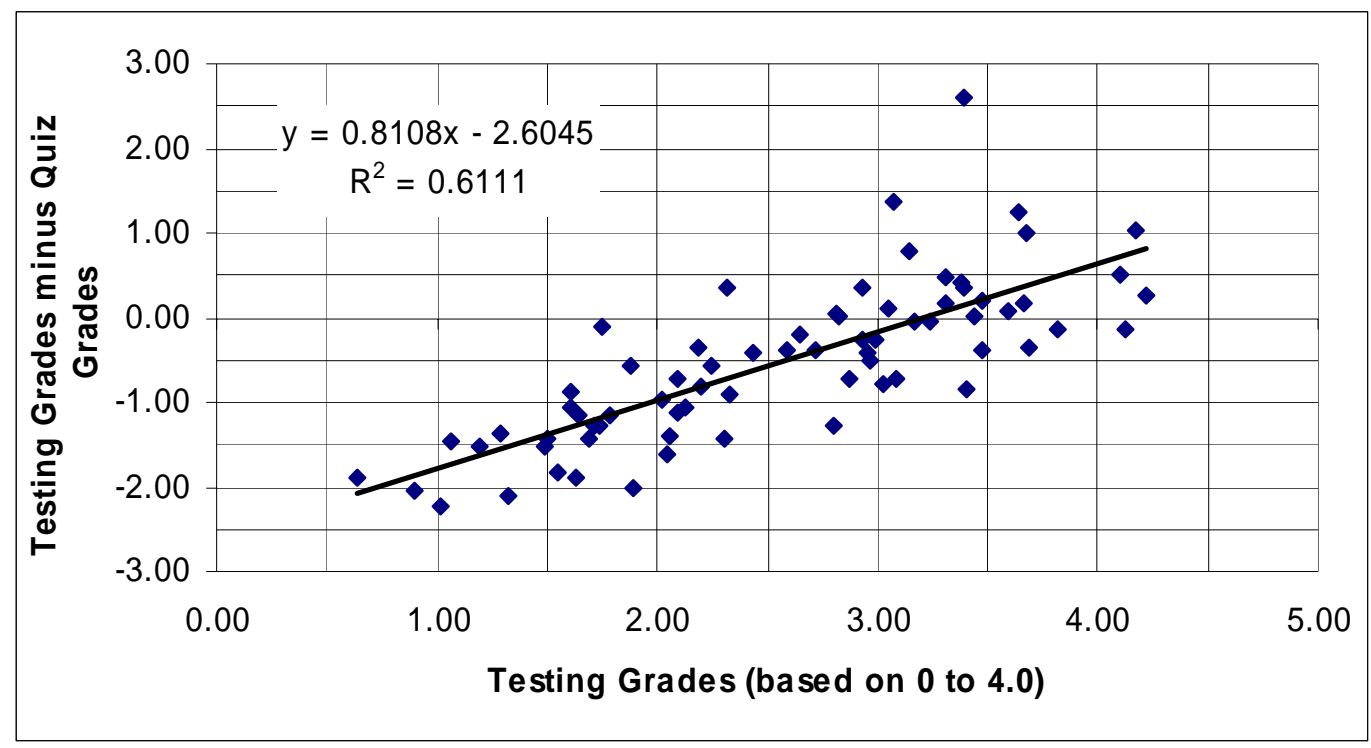

Figure 2. Testing Grades Minus Quiz Grades vs. Testing Grades (Fall 2006)

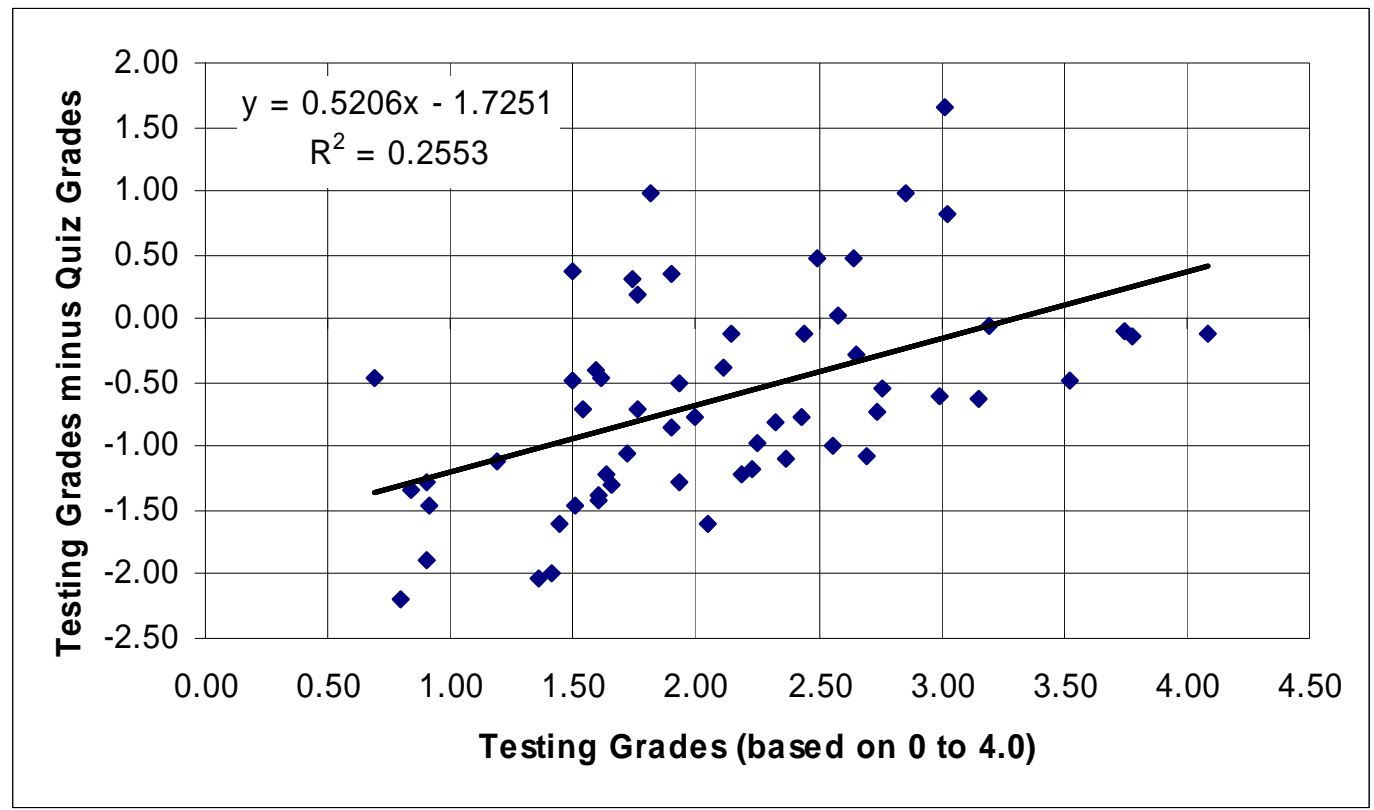

Figure 3. Testing Grades Minus Quiz Grades vs. Testing Grades (Fall 2007) 
Table 2. Responses from End-of-the Semester Survey

( 5 = "strongly agree; 4 = "agree"; 3 = "no preference"; 2 = "disagree"; and 1 = "strongly disagree")

\begin{tabular}{|l|l|l|l|l|l|l|l|l|}
\hline $\mathbf{2 0 0 6}$ & $\mathbf{2 0 0 7}$ & $\mathbf{a v g}$ & I feel confident I can solve engineering problems & $\mathbf{5}$ & $\mathbf{4}$ & $\mathbf{3}$ & $\mathbf{2}$ & $\mathbf{1}$ \\
\hline 4.44 & 4.51 & $\mathbf{4 . 4 7}$ & using the steam table. & 66 & 49 & 4 & 1 & 1 \\
\hline 4.39 & 4.41 & $\mathbf{4 . 4 0}$ & using the air table. & 62 & 48 & 9 & 1 & 1 \\
\hline 3.70 & 3.67 & $\mathbf{3 . 6 9}$ & using ideal gases with constant specific heats. & 27 & 45 & 36 & 10 & 3 \\
\hline 4.21 & 4.33 & $\mathbf{4 . 2 6}$ & involving vapor power cycles ,e.g., Rankine cycles. & 53 & 51 & 14 & 2 & 1 \\
\hline 3.97 & 3.98 & $\mathbf{3 . 9 8}$ & involving closed gas power cycles, e.g., IC engines. & 34 & 56 & 24 & 5 & 1 \\
\hline 4.23 & 4.02 & $\mathbf{4 . 1 4}$ & involving open gas power cycles, e.g., Brayton cycles. & 44 & 55 & 17 & 2 & 2 \\
\hline 4.23 & 3.98 & $\mathbf{4 . 1 2}$ & involving vapor compression refrigeration cycles. & 47 & 48 & 22 & 2 & 2 \\
\hline 4.13 & 3.47 & $\mathbf{3 . 8 6}$ & involving air-water vapor mixtures, e.g., psy chart. & 37 & 46 & 25 & 9 & 4 \\
\hline 3.96 & 3.24 & $\mathbf{3 . 6 6}$ & involving the combustion of hydrocarbons. & 26 & 45 & 45 & 10 & 4 \\
\hline & & & & & & & & \\
\hline 4.60 & 4.24 & $\mathbf{4 . 4 5}$ & Using Blackboard presents no problems for me. & 80 & 23 & 10 & 5 & 2 \\
\hline 4.09 & 3.75 & $\mathbf{3 . 9 5}$ & I prefer using Blackboard over getting handouts. & 59 & 20 & 23 & 14 & 5 \\
\hline 4.27 & 4.33 & $\mathbf{4 . 3 0}$ & Having notes on Blackboard was useful. & 72 & 28 & 10 & 7 & 4 \\
\hline 2.83 & 2.49 & $\mathbf{2 . 6 9}$ & I would prefer notes written out on the whiteboard. & 21 & 17 & 25 & 19 & 39 \\
\hline 4.15 & 3.53 & $\mathbf{3 . 8 8}$ & I liked the fact that there was no homework. & 56 & 24 & 17 & 13 & 9 \\
\hline 4.33 & 3.75 & $\mathbf{4 . 0 9}$ & The posted examples were useful. & 55 & 38 & 15 & 9 & 4 \\
\hline 2.14 & 2.96 & $\mathbf{2 . 4 9}$ & I prefer weekly homework assignments. & 15 & 15 & 22 & 31 & 38 \\
\hline 4.08 & 3.33 & $\mathbf{3 . 7 5}$ & I prefer the weekly quizzes. & 43 & 32 & 23 & 8 & 11 \\
\hline 3.26 & 2.88 & $\mathbf{3 . 1 0}$ & I prefer having only exams and quizzes. & 27 & 25 & 21 & 25 & 21 \\
\hline 1.94 & 2.12 & $\mathbf{2 . 0 2}$ & I prefer having only exams on which to base grades. & 10 & 4 & 19 & 31 & 55 \\
\hline 3.00 & 3.29 & $\mathbf{3 . 1 2}$ & The project was a good thing. & 25 & 27 & 28 & 20 & 21 \\
\hline 2.81 & 2.63 & $\mathbf{2 . 7 3}$ & The project was a bad thing. & 19 & 17 & 30 & 21 & 33 \\
\hline 3.56 & 3.61 & $\mathbf{3 . 5 8}$ & I learned interesting things from the project. & 31 & 43 & 25 & 9 & 13 \\
\hline 4.20 & 3.94 & $\mathbf{4 . 0 9}$ & I better understand how MEs use thermodynamics. & 41 & 56 & 18 & 3 & 2 \\
\hline
\end{tabular}

the ideal gas with constant specific heat model. Most students are very comfortable with a website format but seven (of 120) indicated they had "problems" with Blackboard. (There was a request for comments on the survey and a specific request for comments associated with this statement, but none was offered to indicate what the problems were. However, there were four students who never bothered to have their email aliases changed to receive email from Blackboard. All students were listed in the course inventory implying that they all had access to Blackboard.) Nineteen indicated that they preferred receiving hard copies of the class hand outs over the electronic availability through BlackBoard. (The current printer policy at the University of Houston is that students get about 1000 free pages printed a semester before being charged.) Eleven students did not find the electronic notes useful. Thirty-eight students indicated that they would prefer that lecture notes be written out on the white board over viewing them on a PowerPoint presentation. (Other instructors in our Department have heard this comment before. The basis seems to be the feeling that writing on the board "slows" the pace of instruction which some students view as "good".) The next six statements address the issue of quizzes vs. homework. About $15 \%$ of the students indicated that they prefer homework while about $65 \%$ preferred the quizzes. The fact that over $10 \%$ did not find the posted examples useful seems to

Proceedings of the 2008 ASEE Gulf-Southwest Annual Conference

The University of New Mexico - Albuquerque

Copyright (C) 2008, American Society for Engineering Education 
indicate that perhaps this group wasn't too interested in the course in the first place and would seem to shift some the responses on the Blackboard issues a little more in the favor of Blackboard for the serious students. Only about $10 \%$ indicated that they would prefer using only exams to determine their grades. About $40 \%$ supported having a "project" and about the same proportion did not. However, less than $20 \%$ indicated that they did not "learn some interesting things from the project." Finally, over $80 \%$ indicated that they "better understand how MEs use thermodynamics" and less than $4 \%$ indicated that they did not.

\section{Conclusions}

The use of closed book quizzes in place of traditional homework appears not to have improved student learning, at least that learning that can be determined from open book testing. On the other hand the ten quizzes reduced class lecture time by approximately $15 \%$ which either had no effect on grades or perhaps its negative effect was balanced by any positive effect that the quizzes may have had in forcing the students to "keep up" better. It is also clear that the quiz grades are not a better predictor of testing performance than are homework grades, although homework grades appear to be more inflated. Based on Figs. 1 through 3 it seems that better performances on either homework (even though for some it may not be their own work) or quizzes, portent for better performances on testing in the course.

\section{References}

1. Moran, Michael J, and Howard N. Shapiro, Fundamentals of Engineering Thermodynamics, 5th Edition, John Wiley \& Sons, Inc. 2004.

\section{RICHARD BANNEROT}

Richard Bannerot is a professor of mechanical engineering at the University of Houston. His research interests are in the thermal sciences and engineering education, especially heat transfer, alterative energy, thermal system design, and design education. He is a registered professional engineer in the State of Texas. 


\section{APPENDIX I: QUIZ TOPICS}

Topics for Closed Book Quizzes for fall 2006

1. Stating definitions from a posted list of terms from Thermodynamics I

2. Reading the Steam Table

3. Using Enthalpy Departure Calculations

4. Determining by-pass ratios for regenerated Rankine cycles

5. Drawing T-s diagrams for "real" air power cycles

6. Using p-h diagrams to solve "real" vapor compression refrigeration cycles

7. Reading the Psychrometric chart

8. Calculating thermal loads and mass transfers with psychrometric charts

9. Calculating molar and mass air-fuel ratios for complete combustion

10. Calculating molar and mass air-fuel ratios for incomplete combustion

Topics for Closed Book Quizzes for fall 2007

1. Stating definitions and units conversion factors from a posted list of terms from Thermodynamics I

2. Reading the Steam Table and performing First Law calculations

3. Solving Rankine cycles with superheat and reheat

4. Solving Rankine cycles with regeneration

5. Solving air power cycles with the Air Tables

6. Using p-h diagrams to solve "real" vapor compression refrigeration cycles

7. Reading the Psychrometric chart

8. Calculating thermal loads and mass transfers with psychrometric charts

9. Calculating molar and mass air-fuel ratios for complete combustion

10. Calculating molar and mass air-fuel ratios for incomplete combustion 


\section{APPENDIX II: QUIZZES FOR FALL 2007}

These are the actually four versions of each quizzes; two quizzes per section for the two sections taught in fall 2007. Quizzes are all closed book and students are allowed 15 to 25 minutes for each quiz.

The following information (plus Steam or Air Tables as needed) was given with all but the first quiz:

$$
\begin{aligned}
& 1 \mathrm{~N}=\mathrm{kg} \mathrm{m} / \mathrm{s}^{2} \text { or } 1=(\mathrm{kg}-\mathrm{m}) /\left(\mathrm{N}-\mathrm{s}^{2}\right) \\
& 1 \mathrm{lb}_{\mathrm{f}}=32.2\left(\mathrm{lb}_{\mathrm{m}}-\mathrm{ft}\right) / \mathrm{s}^{2} \text { or } 1=32.2\left(1 \mathrm{~b}_{\mathrm{m}}-\mathrm{ft}\right) /\left(\mathrm{lb}_{\mathrm{f}}-\mathrm{s}^{2}\right) \\
& 1 \mathrm{~Pa}=1 \mathrm{~N} / \mathrm{m}^{2} \\
& 1 \mathrm{~J}=1 \mathrm{~N} \mathrm{~m} \\
& 1 \mathrm{~kg}=2.2 \mathrm{lb}_{\mathrm{m}} \\
& 1 \text { in. }=2.5 \mathrm{~cm} \\
& 1 \mathrm{ft}^{3}=7.5 \mathrm{gal} \\
& 1 \mathrm{lb}_{\mathrm{f}}=4.4 \mathrm{~N} \\
& 1 \mathrm{~atm}=14.7 \mathrm{psi}=1 \mathrm{bar}=101 \mathrm{kPa} \\
& 1 \mathrm{~kJ} \approx 0.95 \mathrm{Btu} \approx 1 \mathrm{Btu} \\
& 1 \mathrm{Btu}=778 \mathrm{ft}-1 \mathrm{~b}_{\mathrm{f}} \\
& 1 \mathrm{hp}=550\left(\mathrm{ft}-\mathrm{lb}_{\mathrm{f}}\right) / \mathrm{s} \approx 0.75 \mathrm{~kW} \\
& 1 \mathrm{Btu} /\left(\mathrm{lb}_{\mathrm{m}}-{ }^{\circ} \mathrm{R}\right)=4.2 \mathrm{~kJ} /(\mathrm{kg}-\mathrm{K}) \\
& \text { Molar gas constant: } \bar{R}=1.986 \mathrm{Btu} /\left(\mathrm{lb}_{\mathrm{m}} \mathrm{mole}-{ }^{\circ} \mathrm{R}\right) \\
& \mathrm{R}_{\text {air }}=2 / 29=0.69 \mathrm{Btu} /\left(\mathrm{lbm}-{ }^{\circ} \mathrm{R}\right) \\
& \approx 2 \mathrm{Btu} /\left(\mathrm{lb}_{\mathrm{m}} \text { mole }-{ }^{\circ} \mathrm{R}\right) \\
& \mathrm{c}_{\mathrm{p}}(\mathrm{T})=\mathrm{c}_{\mathrm{v}}(\mathrm{T})+\mathrm{R} \\
& \mathrm{c}_{\mathrm{p}}(\mathrm{T})=\mathrm{k}(\mathrm{T}) \mathrm{R} /(\mathrm{k}(\mathrm{T})-1)
\end{aligned}
$$

Energy Equation: 1D, steady state, one inlet and one outlet:

$\mathrm{CV}$ work rate $=\mathrm{CV}$ heat transfer rate $+\dot{m}\left[\left(\mathrm{~h}_{1}-\mathrm{h}_{2}\right)+\left(\mathrm{vel}_{1}{ }^{2}-\mathrm{vel}_{2}{ }^{2}\right) / 2+\mathrm{g}\left(\mathrm{z}_{1}-\mathrm{Z}_{2}\right)\right]$ 


\section{Quiz 1A}

Determine the expression on the right that best corresponds to the symbol on the left and the place the associated lower case letter on the line. A letter can be used only once, but of course not all letters will be used.

\begin{tabular}{|c|c|}
\hline & a. $(\mathrm{kg}-\mathrm{m}) / \mathrm{s}^{2}$ \\
\hline \multirow{2}{*}{$\mathrm{Pa}$} & b. $0.75 \mathrm{~kW}$ \\
\hline & c. $0.286 \mathrm{~kJ} /(\mathrm{kg}-\mathrm{K})$ \\
\hline \multirow[t]{2}{*}{$\mathrm{R}_{\text {air }}$} & $\begin{array}{l}\text { d. } 32.21 \mathrm{lb}_{\mathrm{m}}-\mathrm{ft} / \mathrm{s}^{2} \\
\text { e. Btu }\end{array}$ \\
\hline & f. $1 \mathrm{Btu} /\left(\mathrm{lb}_{\mathrm{m}}{ }^{\mathrm{o}} \mathrm{R}\right)$ \\
\hline \multirow[t]{2}{*}{$\mathrm{lb}_{\mathrm{f}}$} & g. $0.78 \mathrm{Btu} /\left(\mathrm{lb}_{\mathrm{m}^{-}}{ }^{\mathrm{o}} \mathrm{R}\right)$ \\
\hline & h. $15 \mathrm{~kJ} /(\mathrm{kmol}-\mathrm{K})$ \\
\hline \multirow[t]{2}{*}{$\mathrm{C}_{\mathrm{P} \text { air }}$} & i. $101 \mathrm{~Pa}$ \\
\hline & j. $\quad 778 \mathrm{ft}-\mathrm{lb}_{\mathrm{f}}$ \\
\hline \multirow[t]{2}{*}{$\bar{R}$} & k. $\quad 1 b_{m}-f t / s^{2}$ \\
\hline & $1 \quad 0.24 \mathrm{Btu} /\left(\mathrm{lb}_{\mathrm{m}}{ }^{\circ}{ }^{\circ} \mathrm{R}\right)$ \\
\hline $\mathrm{N}$ & $\begin{array}{l}\text { m. } 2 \mathrm{Btu} /\left(\mathrm{lb}_{\mathrm{m}}-\mathrm{mole}^{\mathrm{o}}\right) \\
\text { n. } \quad(\mathrm{g}-\mathrm{m}) / \mathrm{s}^{2}\end{array}$ \\
\hline \multirow[t]{2}{*}{ hp } & o. 10.0 psia \\
\hline & p. $\quad \mathrm{N} / \mathrm{m}^{2}$ \\
\hline \multirow[t]{2}{*}{$\mathrm{kJ}$} & q. $5 \mathrm{~kW}$ \\
\hline & r. $\quad 4.4 \mathrm{~N}$ \\
\hline $1 \mathrm{ft}^{3}$ & $\begin{array}{ll}\text { s. } & 7.5 \mathrm{gal} \\
\text { t. } & 101 \mathrm{kPa}\end{array}$ \\
\hline
\end{tabular}

Write definitions of the following terms:

State:

Closed System:

Property:

Extensive Property

Quasiequilibrium Process

Quiz 2A

Steam at 160 . psia, $600 .{ }^{\circ} \mathrm{F}$ enters a turbine operating at steady state at the rate of $20.1 \mathrm{~b}_{\mathrm{m}} / \mathrm{min}$ and exits at 20. psia, 300. ${ }^{\circ} \mathrm{F}$. Determine the power produced in hp. State your assumptions.

Air (assumed to behave as an ideal gas with $\mathrm{MW}=29$ ) flowing at $4.0 \mathrm{~kg} / \mathrm{s}$ is adiabatically compressed from $200 . \mathrm{kPa}, 100 .{ }^{\circ} \mathrm{C}$ to $1.00 \mathrm{MPa}, 380 .{ }^{\circ} \mathrm{C}$. Determine the power required. State your assumptions. 


\section{Quiz 3A}

Draw a schematic and a matching T-s diagram for a Rankine cycle with superheat labeling the states around the cycle beginning with 1 at the turbine entrance. The turbine efficiency is $85 \%$ and steam flow rate is $100 \mathrm{~kg} / \mathrm{s}$. For a boiler pressure of $6.0 \mathrm{MPa}$, a condenser pressure of 0.07 $\mathrm{MPa}$ and maximum cycle temperature of $440 .{ }^{\circ} \mathrm{C}$, determine the turbine power output and the condenser heat dissipation.

\section{Quiz 4A}

Draw an equipment schematic and matching T-s and h-s diagrams for a Rankine cycle with superheat and regeneration with an open feedwater heater (with NO reheating). Label the states around the cycle beginning with 1 at the turbine entrance. Assume a turbine efficiency of 100\% and steam flow rate of $2.0 \mathrm{~kg} / \mathrm{s}$. For a boiler pressure of $6.00 \mathrm{MPa}(60$. bars), an extraction pressure of $1.00 \mathrm{MPa}(10$. bars), a condenser pressure of $0.0100 \mathrm{MPa}(0.10 \mathrm{bar})$, and maximum cycle temperature of $440 .{ }^{\circ} \mathrm{C}$, determine the extraction fraction for the open feedwater heater.

\section{Quiz 5A}

Draw a T-s and a p-v diagram for the air-standard Otto cycle indicating the beginning of the isentropic compression as " 1 " on both diagrams and continuing the numbering in the direction of the processes.

Set up the procedure for determining the HEAT ADDED (only) for an air-standard Otto cycle when the given information is: the cycle compression ratio, the temperature and pressure at the beginning of the isentropic compression, and the maximum pressure for the cycle. (That is, write the equations which need to be used and indicate the "steps" required to obtain the numerical values.)

Determine the HEAT ADDED (in Btu/lb $b_{m}$ ) when the compression ratio is 5.00, the pressure and temperature at the beginning of the isentropic compression are 15.0 psia and $500 .{ }^{\circ} \mathrm{R}$, respectively, and the maximum pressure is 500. psia. (Estimate the interpolations)

\section{Quiz 6A}

Determine the COP of the refrigeration cycle described below using refrigerant Suva 404A (ph diagram attached). Locate the appropriate states and the processes on the diagram, and number the states counterclockwise around the cycle beginning with " 1 " at the compressor inlet.

Assume the environment (warm region) is at 100. ${ }^{\circ} \mathrm{F}$ and the "cold" space (cold region) is at 20. ${ }^{\circ} \mathrm{F}$. The evaporator and condenser are designed to operate with a $20 .{ }^{\circ} \mathrm{F}$ temperature difference with their respective heat source or heat sink, i.e., between its fluid temperature and the temperature of its associated warm or cold region. Assume $10 .{ }^{\circ} \mathrm{F}$ of superheating at the evaporator exit and $20 .{ }^{\circ} \mathrm{F}$ of subcooling at the condenser exit. The compressor efficiency is $75 \%$. 


\section{Quiz 7A}

Air enters the compressor of an ideal Brayton refrigeration cycle at $1 \mathrm{~atm},-13.0^{\circ} \mathrm{C}$ (minus 13) with a flow rate of $2.0 \mathrm{~kg} / \mathrm{s}$. If the compressor pressure ratio is 5.0 and the turbine inlet temperature is $47.0^{\circ} \mathrm{C}$, determine the cycle COP. Draw a T-s diagram of the cycle labeling the significant states counter-clockwise from 1 at the compressor entrance. Preferably work the problem in the space provided below.

\section{Quiz 8A}

Using the attached Psychrometric Chart, locate the state: dry bulb temperature $=20.0^{\circ} \mathrm{C}$, specific humidity $=0.010$. Determine for this state the following quantities and write them in the space provided (indicating the appropriate units):

The dew point:

The wet bulb temperature:

Relative humidity:

$\mathrm{h}^{*}$ (enthalpy per kg of dry air):

$\mathrm{V}^{*}$ (volume per kg of dry air):

Determine the heating load (heat transfer) in $\mathrm{kW}$ to heat this moist air to $40.0{ }^{\circ} \mathrm{C}$ at the rate of $100 \mathrm{~m}^{3} / \mathrm{min}$.

\section{Quiz 9A}

Determine the air-fuel ratio on both a molar and mass basis for the complete combustion of ethane $\left(\mathrm{C}_{2} \mathrm{H}_{6}\right)(\mathrm{MW}=30.07)$.

\section{Quiz 10A}

Determine the air-fuel ratio on both a molar and mass basis for the complete combustion of ethane $\left(\mathrm{C}_{2} \mathrm{H}_{6}\right)($ molecular weight $=30.07)$ in $100 \%$ theoretical air.

If products of an actual combustion of ethane in dry air results in the following molar analysis of the dry products: $7.7 \% \mathrm{CO}_{2}, 1.4 \% \mathrm{CO}, 7.1 \% \mathrm{O}_{2}$ and $83.8 \% \mathrm{~N}_{2}$, what was the per cent excess air provided for the process? 


\section{APPENDIX III: PROJECT ASSIGNMENT FOR FALL 2007}

\section{MECE 3334: Thermodynamics II \\ Projects \\ Fall 2007}

October 9, 2007

Assigned: October $9^{\text {th }}$

Due: November 29th

Research individually a topic selected from the list at the end of this document or propose your own topic. Prepare two written documents (details below):

1. a technical report and

2. a two-page extended abstract.

The form of the technical report may vary depending on the topic, but should include as a minimum:

- a cover page (project title, course name and number, date, and your name)

- an abstract (maximum of 250 words)

- $\quad$ problem statement (maximum of 50 words, $2^{\text {nd }}$ person is ok here)

- introduction (including context and background)

- main body of the report divided into an appropriate number of sections

- conclusions (maximum of 400 words)

- “back matter" as needed, e.g., appendix, references, etc.

Figures and tables should be integrated into the text. The report should be typed, (double spaced, 12 font) and is limited to about 4000 words (abstract through conclusions) not counting the "back matter".

The extended abstract should be no more than one page of text (single spaced, 12 font), and one page of figures/tables (at most 4 figures/tables). The extended abstract is intended to be printed on one sheet of paper using both the front and the back. The extended abstract is intended for an audience that will NOT see the full report. This document is similar to the "executive summary" described in Finkelstein (ENGI 2304) and Beer (MECE 2361). The course name and number, project title, your name and the date should be at the top of the first (text) page.

For submission the extended abstract should be placed on top of the technical report and all pages secured with a single staple in the upper left corner. The audience for both papers is a junior-level, mechanical engineering student. 


\section{List of Suggested Topics}

Some of the topics are followed by issues that should be addressed, but your report is not to be limited to that issue. You should address the general topic first and then address the specific issue.

1. Global Warming. What is it? How does it occur? What is the evidence pro and con? Include the issue of whether human activity is contributing to this phenomenon. If human activity is contributing, what can be done?

2. Sustainable Development: What is it? Why is it an issue? Provide examples of both sustainable and un-sustainable development.

3. Energy from renewable "bio-sources" and waste materials: What are the possibilities? Discuss the possibility for widespread generation of electricity from these resources in the US. Include issues related to economics, availability of the resource in both time and space, and the social, political, and environmental issues.

4. Wind Energy: How is it produced? What are the technologies? Discuss the possibility for widespread generation of electricity by this resource in the US. Include issues related to economics, availability of the resource in both time and space, and the social, political, and environmental issues.

5. Solar Energy: How is it "produced"? What are the technologies? Discuss the possibility for widespread generation of electricity by this resource in the US. Include issues related to economics, availability of the resource in both time and space, and the social, political, and environmental issues.

6. Nuclear Energy: How is it produced? What are the technologies? What it is history? Discuss the possibility for widespread generation of electricity by this resource in the US. Include issues related to economics, availability of the resource in both time and space, and the social, political, and environmental issues.

7. Crude oil as a resource and an energy source: Discuss the various uses for crude oil (energy as well as others). What fraction of crude oil produced is allocated to these various uses?

8. Crude oil production: Discuss the history of the production of crude oil (how we get it out of the ground and how we get it to the refinery) and its production history (how many barrels produced each year, past, present and future projection [address the issue of "peak oil"]).

9. Energy storage technologies: Discuss how these technologies may "fit" with intermittent resources, e.g., solar and wind, and as a "fuel" for transportation. 
10. The relative cost of electricity generation: Include coal, oil, gas, nuclear, wind, hydo, and solar (both the parabolic thermal plants in California and large photo-voltaic systems) generating plants. Determine the amounts of electricity generated in the US from each these technologies.

11. A hydrogen economy: What is it? Discuss its feasibility, pros and cons, and likelihood of developing.

12. The environmental impact of energy conversion to electricity: For example, air and water pollution due to mining, transporting and burning coal; lost of habitat, flora and fauna from the damning of rivers to produce hydro-electric power; and other quality of life and human health issues.

13. Mining space for energy and/or any other "way out there" ideas: For example, energy from the planets or solar energy collected in space and "beamed" back to Earth.

14. History of refrigeration technology: Emphasize the basic thermodynamics of the various processes.

15. History of the development of large-scale electrical energy distribution networks: How does the US national electrical grid work to keep us dependably provided with electricity in our homes?

16. Water as a resource: Are we in trouble in the US? in the world?

17. Coal as an energy resource. What are the consequences of large scale coal use for producing electricity?

18. Energy from alternative fossil sources, e.g., tars sands and shale: What are the technological, economic, environmental, social, and political challenges?

19. Energy from geothermal sources: What are the technological, economic, environmental, social, and political challenges?

20. Energy from the ocean, e.g., tidal, waves and ocean thermal gradient: What are the technological, economic, environmental, social, and political challenges?

21. Green buildings: What are they and what is their potential contribution to energy savings?

22. Energy use in the transportation sector. An overview of energy needs and uses for land, air, and sea travel. 